\title{
The response of vegetation growth to shifts in trend of temperature in China
}

\author{
HE Bin ${ }^{1}$, CHEN Aifang ${ }^{2}$, JIANG Weiguo ${ }^{3}$, CHEN Ziyue $^{1}$
}

1. State Key Laboratory of Earth Surface Processes and Resource Ecology, College of Global Change and Earth System Science, Beijing Normal University, Beijing 100875, China;

2. Regional Climate Group, Department of Earth Sciences, University of Gothenburg, Box 460, 40530 Gothenburg, Sweden;

3. Academy of Disaster Reduction and Emergency Management, Beijing Normal University, Beijing 100875, China

\begin{abstract}
Though many studies have focused on the causes of shifts in trend of temperature, whether the response of vegetation growth to temperature has changed is still not very clear. In this study, we analyzed the spatial features of the trend changes of temperature during the growing season and the response of vegetation growth in China based on observed climatic data and the normalized difference vegetation index (NDVI) from 1984 to 2011. An obvious warming to cooling shift during growing season from the period 1984-1997 to the period 1998-2011 was identified in the northern and northeastern regions of China, whereas a totally converse shift was observed in the southern and western regions, suggesting large spatial heterogeneity of changes of the trend of growing season temperature throughout China. China as a whole, a significant positive relationship between vegetation growth and temperature during 1984 to 1997 has been greatly weakened during 1998-2011. This change of response of vegetation growth to temperature has also been confirmed by Granger causality test. On regional scales, obvious shifts in relationship between vegetation growth and temperature were identified in temperate desert region and rainforest region. Furthermore, by comprehensively analyzing of the relationship between NDVI and climate variables, an overall reduction of impacts of climate factors on vegetation growth was identified over China during recent years, indicating enhanced influences from human associated activities.
\end{abstract}

Keywords: vegetation growth; temperature; shift; response; NDVI; China

\section{Introduction}

Shifts of temperature trends during the 21 st century, despite continued increases in atmospheric greenhouse gas concentrations, have been discussed by many recent studies (Boykoff, 2014; Kosaka and Xie, 2013; Trenberth et al., 2014). Many research efforts have concentrated on exploring the causes of these unexpected shifts (Chen and Tung, 2014; Meehl et al., 2014; Thompson et al., 2014); however, whether and how the influence of temperature on

Received: 2016-09-02 Accepted: 2017-01-20

Foundation: National Natural Science Foundation of China, No.41671083, No.41301076

Author: He Bin (1981-), Associate Professor, specialized in studies on impacts of climate extremes.

E-mail: hebin@bnu.edu.cn 
terrestrial ecosystems has changed is still poorly understood. Over the past several decades, climate warming has been considered to be the main driving force for vegetation growth in northern terrestrial ecosystems (Nemani et al., 2003). Hence, this raises the question of whether the temperature trend shifts will reduce the positive effect of increased temperature on vegetation growth.

Evidence of the temperature trend shifts have been observed in China (Li et al., 2015). Specifically, from 1998 to 2012, the annual mean maximum and minimum temperature decreased by $-0.39^{\circ} \mathrm{C}$ decade $^{-1}$ and $-0.13^{\circ} \mathrm{C}$ decade $^{-1}$ but increased by $0.08^{\circ} \mathrm{C}$ decade $^{-1}$ and $0.33^{\circ} \mathrm{C}$ decade $^{-1}$ from 1961 to 1997 , respectively (Li et al., 2015). Over the past three decades, climate change, especially increasing temperatures, which boosted vegetation growth by enhancing photosynthesis and prolonging the growing season (Ge et al., 2015; Peng et al., 2011; Ding et al., 2015; Li et al., 2013; Liu et al., 2014; Yin et al., 2016; Zhang et al., 2013), has greatly influenced vegetation growth in China. A large body of studies has investigated the dynamics of vegetation growth and their response to climate change based on time series of remote sensing vegetation data (Fang et al., 2004; Peng et al., 2011; Piao et al., 2014; Xu et al., 2012; Zhang et al., 2012; Ding et al., 2007; Zhang et al., 2009). A recent study has suggested a reduction in vegetation growth in China since the late 1990s (Peng et al., 2011), raising the question of whether this trend is associated with the change of the temperature trend beginning from 1998.

Although many studies have explored the response of vegetation growth to temperature in China, the majority of them are static assessment and ignore the nonlinear response of vegetation growth to temperature. Few scholars have focused on the dynamic features of this response over time. Variations in the effects of temperature on vegetation growth have been observed by some biome and region specific studies (Piao et al., 2014; Wu et al., 2012). For example, Piao et al. (2014) suggested a weakened positive relationship between temperature and vegetation activity in northern ecosystems. Understanding the dynamic response of vegetation activity to temperature change is crucial for predicting future vegetation growth. The recent warming shift provides us with an opportunity to investigate variations in plant growth under accelerated and decelerated warming conditions. Hence, the goals of this study are to (1) examine whether the relationship between vegetation growth and temperature has changed before and after temperature shift, and (2) explore the potential mechanism behind the change response of vegetation growth to temperature variation.

\section{Data and methods}

\subsection{Data}

The normalized difference vegetation index (NDVI) is a widely used indicator of vegetation growth. In this study, we used the NOAA/AVHRR NDVI GIMMS3g dataset with a spatial resolution of $0.083^{\circ}$ and a temporal resolution of 15 days from 1982 through 2011, produced by Global Inventory Monitoring and Modeling Studies (GIMMS) (Tucker et al., 2005). This new GIMMS3g dataset is an improved version of GIMMSg with longer time series and higher accuracy. Comparing to the old one, a main improvement is the use of Sea-viewing Wide Field-of view Sensor (SeaWIFS) for calibrating between sensors and validating the accuracy and consistency of the AVHRR time series (Bhatt et al., 2013; Bhatt et al., 2010; 
Pinzon and Tucker, 2010). Discontinuities existing in the GIMMSg (Brown et al., 2006; Tucker et al., 2005) had been effectively corrected, and the new dataset was considered to be comparable to the NASA's Moderate Resolution Imaging Spectroradiometer (MODIS) data with high resolution but shorter time length (Zeng et al., 2013). In line with previous studies, we confined the investigation period to the growing season, from April to October (GS) (Peng et al., 2011; Piao et al., 2011; Tucker et al., 2005; Zhou et al., 2001). The raw NDVI dataset was processed with the following methods. Pixels with an average NDVI value of less than 0.05 from April to October were considered as non-vegetated areas and removed to minimize the impact of soil variations in bare and sparsely vegetated regions (Piao et al., 2011; Zhou et al., 2001). Monthly NDVI datasets were composed using the maximum value composite (MVC) method (Holben, 1986) to further reduce residual cloud contamination and atmospheric and bidirectional effects. The growing season NDVI (GS-NDVI) dataset was obtained by averaging the monthly datasets (Holben, 1986; Fang, 2004). To match with the station observed climate data, we interpolated the grid NDVI to the station locations using the Inverse Distance Weight (IDW) method (Dong et al., 2015). Four grid points surrounding the station were used for interpolating, and the weight is defined as inversely proportional to the distance between the grid point and the station (Wu et al., 2005). Then, the monthly and GS-NDVI sequence data were generated.

The station-based climatic data from 1984 to 2011, including temperature and precipitation, were obtained from China's Meteorological Data Sharing Service System website (http://cdc.nmic.cn/home.do). This dataset was quality controlled prior to publication. Growing season temperature (GS-T) was averaged from the monthly data (April to October), and growing season precipitation (GS-P) was evaluated as the sum of the monthly precipitation over the same period. The climatic data from 518 out of 726 meteorological stations, which were of high quality and covered the study period from 1984 to 2011, were used in the analysis (Figure 1). The other 208 stations were excluded owing to missing data during the growing season. The monthly radiation dataset with a spatial resolution of $0.5^{\circ} \times 0.5^{\circ}$ used in this study was obtained from the CRU NCEP (Climate Research Unit and National Centers for Environmental Prediction), version 5.2 (ftp://nacp.ornl.gov/synthesis/2009/ frescati/). Similar to NDVI data, the grid radiation data were also interpolated to stations using IDW method. Monthly atmospheric $\mathrm{CO}_{2}$ concentration records for the period 1984 to 2011 observed at the Mauna Loa station were collected from National Oceanic and Atmospheric Administration, USA (http://www.esrl.noaa.gov/gmd/ccgg/trends/). We ignored the regional differences of $\mathrm{CO}_{2}$ concentration, and used a unified value over China as previous studies (Ukkola et al., 2015; Wang et al., 2014).

To explore the differences in the response of vegetation growth to temperature change, the study period was divided into two time periods: before and after the warming shift since 1998. This division of study period was defined according to a recent analysis of China temperature trend, which found an obvious trend shift since 1998 (Li et al., 2015). This abrupt change of GS-T may be related to the strong 1997/1998 ENSO event caused tropical sea surface temperature anomalous (Qi and Wang, 2012; Wu et al., 2010). As only 14 years (1998-2011) of NDVI data during warming shift were obtained, only the pre-warming shift data from 1984 to 1997 were used in the comparative analysis. Finally, the two selected periods were 1984-1997 and 1998-2011. 


\subsection{Methods}

The relationships between GS-NDVI and corresponding GS-T were examined on national and regional scales using Kendall-tau correlation analysis. The Kendall-tau has advantages over other correlation analysis methods (e.g., Pearson's correlation analysis) in respect of the smoothness of its distribution and the rapidity with which it approaches normality, thus facilitating significance testing, and in being readily adapted to cases of partial rank correlation (Sillitto, 1947). To explore how the response of vegetation growth to GS-T changed over time, the averaged correlation coefficients between GS-NDVI and GS-T over different periods were calculated by employing 14-year moving windows. The correlation coefficient of a 14-year window was assigned to the year after the central year. For example, 1990 represents the moving window from 1984 to 1997. To further examine the variations in the response of vegetation growth to temperature among regions, the whole country was divided into eight sub-regions according to the distribution of regional representative vegetation type based on Chinese vegetation type division map obtained from the Institute of Botany at the Chinese Academy of Sciences (Figure 1): coniferous forest region (R1), broadleaf-coniferous mixed forest region (R2), deciduous broadleaf forest region (R3), evergreen broadleaf forest region (R4), rainforest region (R5), temperate grassland region (R6), temperate desert region (R7), and Qinghai-Tibet Plateau alpine meadow region (R8). The 518 selected climate stations were classified into eight regions, and the correlations in each region were analyzed. The NDVI trends were tested using Sen's slope method (Sen, 1968), and climatic variable trends were evaluated with the Mann-Kendall (MK) test (Kendall, 1948). Correlations and trends were considered statistically significant at $p<0.01, p<0.05$ and $p<0.1$. Correlations over 10-year and 18-year moving windows were also investigated to examine the sensitivity of correlations to window widths. The data processing and calculations were conducted with the Interactive Data Language (IDL) program, ArcGIS10.1 software, SPSS, and R software.

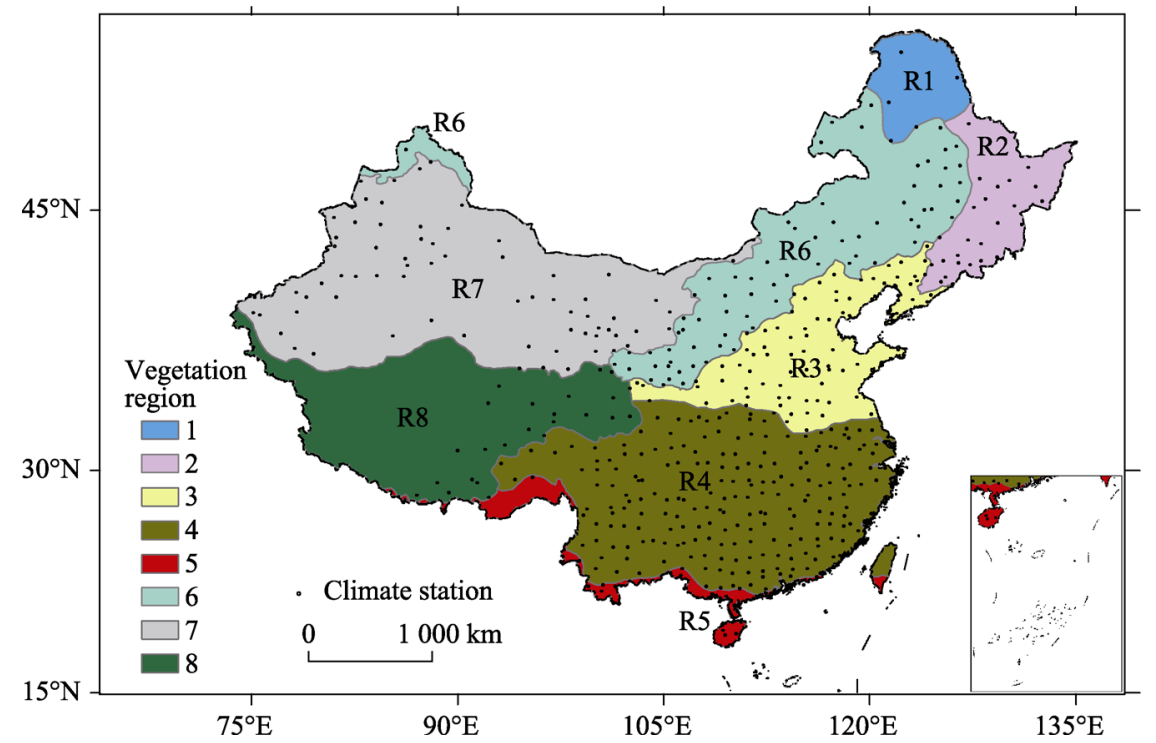

Figure 1 Spatial distribution of studied sub-regions and selected climate stations across China: (1) coniferous forest region, (2) broadleaf-coniferous mixed forest region, (3) deciduous broadleaf forest region, (4) evergreen broadleaf forest region, (5) rainforest region, (6) temperate grassland region, (7) temperate desert region, and (8) Qinghai-Tibet Plateau alpine meadow region 
To support the exploring of the potential mechanisms of impact of GS-T and other climate variables eg growing season precipitation (GS-P), solar radiation (GS-R), $\mathrm{CO}_{2}$ concentration (GS-C) on vegetation growth, Granger causality test was employed here to test the causal links between GS-climate variables and GS-NDVI at national and regional scale. Granger causality test is based on the notion of predictability, and was put forward by Granger in 1969 (Granger, 1969; Mosedale and Stephenson, 2005). This test has been widely applied in the study of interactions between atmosphere and biosphere (Kaufmann et al., 2003; Wang et al., 2004). It has been proved to be an effective technique to detect the causal relationship exclusively between climate factors and vegetation growth (Jiang et al., 2015).

\section{Results}

\subsection{Shifts in trend of temperature over China}

Figure 2 shows the spatial patterns of trends in GS-T across China during 1984-1997 and 1998-2011. High spatial heterogeneity existed during the two periods. From 1984 to 1997 (Figure 2a), most parts of China experienced significant warming, except for some areas in southern China, where negative trends were observed. The average national annual warming rate was $0.25^{\circ} \mathrm{C}$ decade $^{-1}$. From 1998 to 2011 (Figure 2b), an obvious cooling occurred in the northern and northeastern regions of China, whereas the southern and southwestern regions experienced rapid warming. The average national annual warming rate was $0.07^{\circ} \mathrm{C}$ decade $^{-1}$ in this period. The above analysis suggests that obvious shifts in trend of growing season temperature indeed happened in China over above two periods. Since 1998, a shift from warming to cooling was observed in northern regions of China, but a reverse shift was found in southern regions.
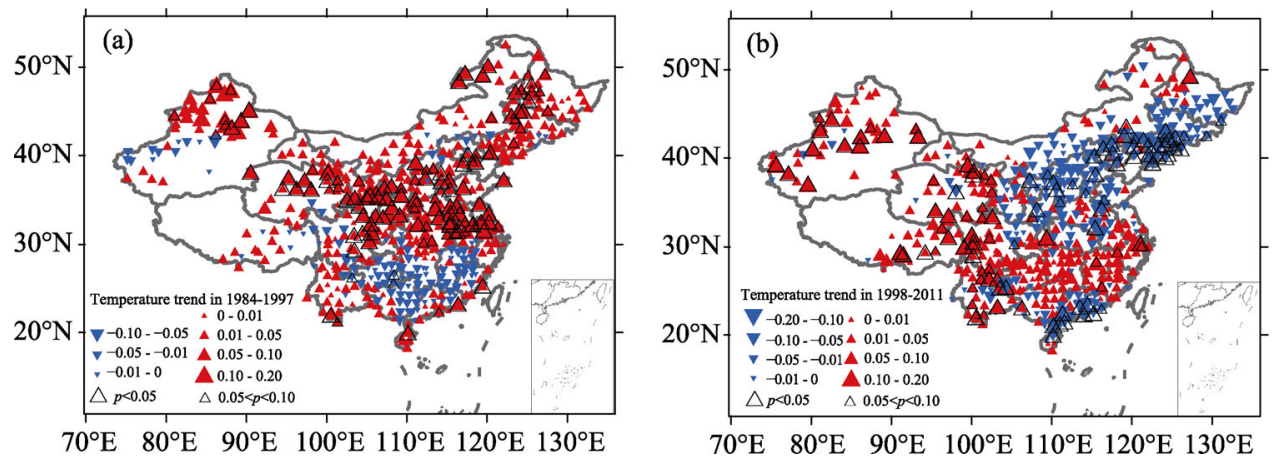

Figure 2 Changes in growing season annual surface air temperature during 1984-1997 (a) and 1998-2011(b). Red triangles indicate warming trends, and blue ones indicate cooling trends.

\subsection{Responses of vegetation growth to shifts of trend of temperature}

Figures $3 \mathrm{a}$ and $3 \mathrm{~b}$ illustrate inter-annual variations in GS-NDVI and corresponding GS-T averaged across 518 stations. Although the overall GS-NDVI $\left(R^{2}=0.27, p<0.01\right)$ and GS-T $\left(R^{2}=0.67, p<0.01\right)$ significantly increased over the entire study period, two clear trends for both variables were observed before and after 1998. From 1984 to 1997, GS-NDVI and GS-T both continually increased. In contrast, from 1998 to 2011, GS-NDVI decreased rap- 
idly, rebounded until 2001, and increased sharply in recent years. An obvious slowing down warming during 1998 to 2011 was identified. Interestingly, an accelerated increase in GS-NDVI occurred during the decelerating warming period.

Figure $3 \mathrm{c}$ shows variations in the correlation coefficient between GS-NDVI and GS-T from 1984 to 2011. Surprisingly, the coefficient significantly decreased $(p<0.01)$ over total 15 windows, in contrast to the significant positive relationship evidenced during earlier years. From 1984 to 1997, there was a significant positive correlation between GS-NDVI and GS-T $(p<0.01)$. However, from 1998 to 2011, a negative correlation was observed between the two variables, although it was not statistically significant $(p>0.05)$. This indicates the sensitivity of vegetation growth to temperature change. The high positive relationship before the warming shift illustrates that increasing temperature promotes vegetation growth, whereas the weak positive relationship during the warming shift indicates a reduced influence of temperature on vegetation growth. The variations in correlation coefficient between GS-NDVI and GS-T calculated based on 10-year and 18-year moving windows (Figure S1) presented similar trends with that based on 14-year windows, suggesting that the width of the moving windows did not affect the trends.
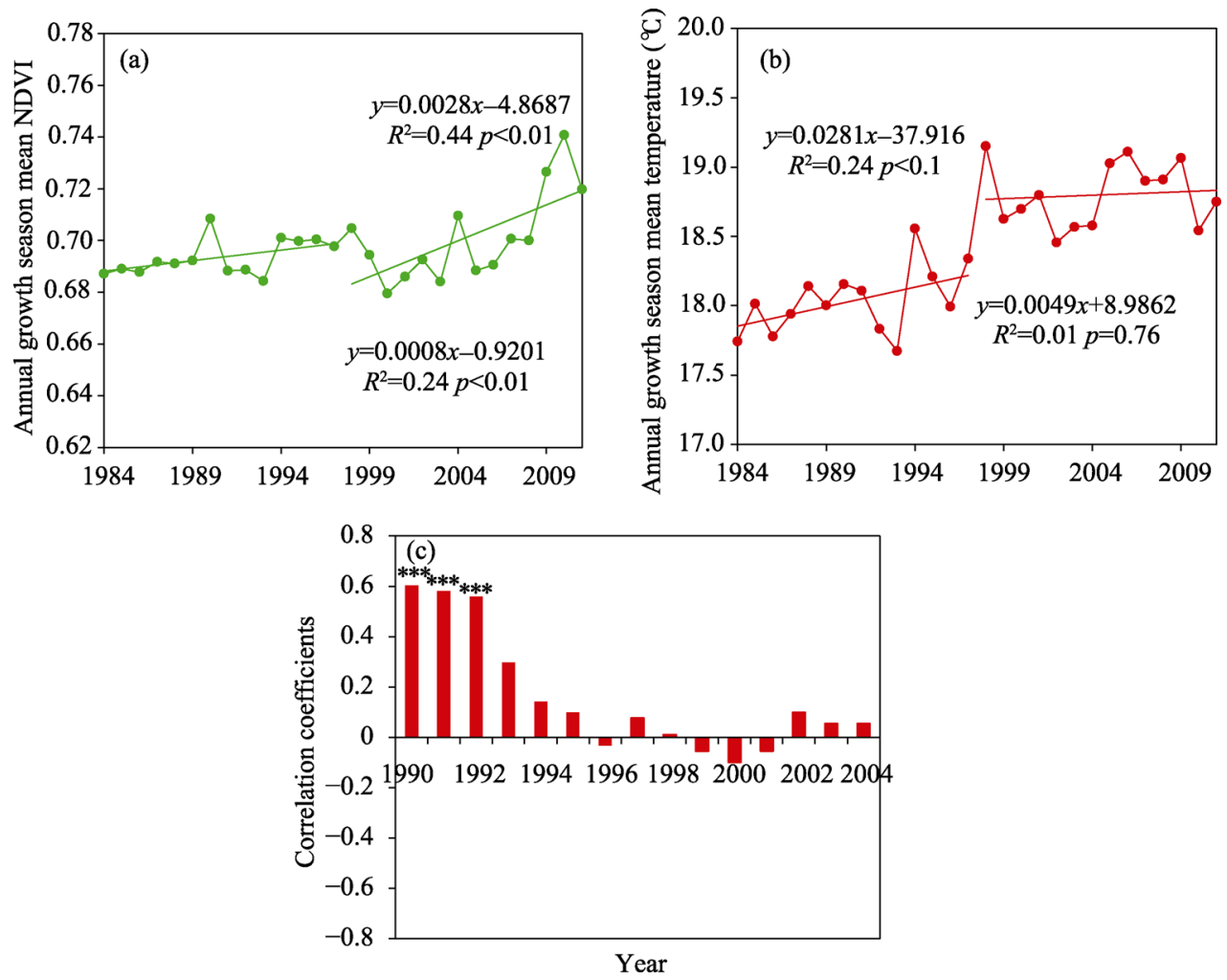

Figure 3 Linear tends of growing season NDVI (a) and corresponding temperature during 1984 to 2011(b); variation of correlation coefficient between growing season NDVI and responding temperature during 1984 to 2011 with 14-year moving windows (c). Correlations with p-values $<0.1,<0.05$ and $<0.01$ are marked with asterisks.

The spatial distribution of the correlation coefficients between GS-NDVI and GS-T during the warming shift (1998-2011) (Figure 4b) changed greatly compared with that during 1984-1997 (Figure 4a). From 1984 to 1997, a positive relationship existed between GS- 
NDVI and GS-T at 241 stations mainly located in the northeastern, central, and southern regions of China. Negative relationships were mainly identified in western areas. From 1998 to 2011, the negative relationships expanded from northern to southern China, and the positive relationships decreased in southern but expanded in western China.
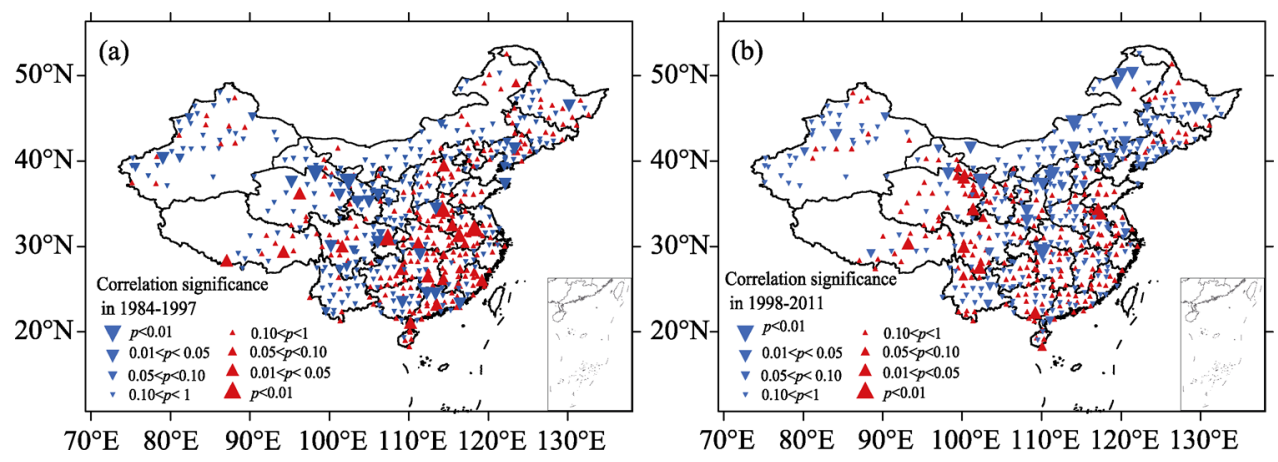

Figure 4 Spatial patterns of correlation coefficient between growing season NDVI and corresponding temperature from 1984 to 1997 (a) and 1998 to 2011 (b). Red triangles indicate positive relationships, and blue ones indicate negative relationships.

In contrast with Figure 2, in the northern and northeastern regions of China, where the warming to cooling shifts occurred, many positive relationships between GS-NDVI and GS-T became negative, indicating the great sensitivity of vegetation growth to temperature change. However, in southern regions of China, where cooling to warming shift occurred, the positive relationships weakened, suggesting a decreased benefit of increasing temperature on vegetation growth. It is interesting that many negative relationships existed during 1984-1998, whereas many positive relationships were evident during 1998-2011 in the Qinghai Tibet Plateau, which experienced accelerated warming during the later period. This suggests that accelerated warming will likely continue to promote vegetation growth. The above analysis suggests that changed responses of vegetation growth to temperature truly happened over two periods at both national and regional scales. In addition, these changes have large spatial differences.

\subsection{Response of growth of different vegetation regions to temperature}

To further explore the response of vegetation growth to temperature variation, the relationships between vegetation growth and temperature were examined in each sub-region. As shown in Figure 5, except for three obvious continuous warming regions, namely, evergreen broadleaf forest region (R4), temperate grassland region (R7) and Qinghai-Tibet Plateau alpine meadow region (R8), all the other regions experienced slowing warming, among which the broadleaf-coniferous mixed forest region (R2), deciduous broadleaf forest region (R3), and temperate grassland region (R6) and rainforests region (R5) experienced the most prominent shift from warming to cooling. Meanwhile, dramatic increases in vegetation growth occurred in the majority of regions from 1998 to 2011, with the exception of temperate desert region (R7). The finding of the weak increase in vegetation growth in R7 is consistent with previous studies (Peng et al., 2011; Zhao et al., 2011), but uncertainty still exists. Vegetation here is sparsely distributed, and its changes may not be sensitive enough to be detected by remote sensors. 

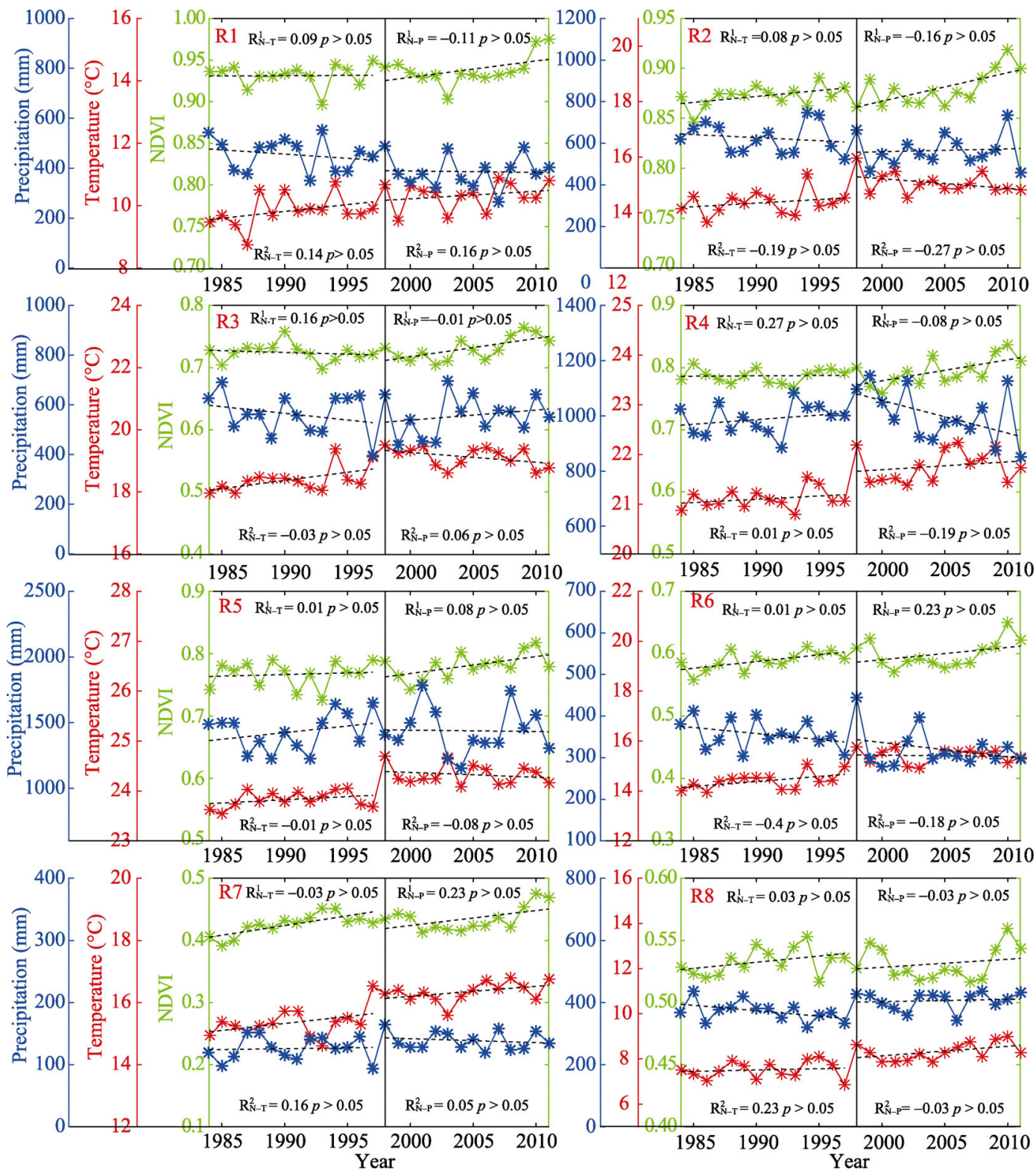

Figure 5 Inter-annual variations of growing season NDVI (green line), mean temperature (red line) and mean precipitation (blue line) in eight sub-regions over the past 28 years. Trend lines denote linear time trends. " $\mathrm{R}_{\mathrm{N}-\mathrm{T}}^{1}$ ",

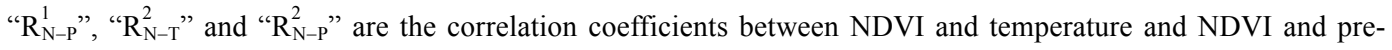
cipitation in 1984-1997 and 1998-2011, respectively.

Notable changes in correlations between GS-NDVI and GS-T happened in each vegetation type region, suggesting great sensitivity of vegetation growth to temperature change. Significant relationships were found in R6 and R2. As mentioned above, these two regions both experienced slowing warming shifts. In R2, the relationship changed little between the two periods, and significant negative relationship occurred during the period 1992-2006 and 1993 to 2007 (Figure 6). In R6, the significant positive effects of temperature on vegetation growth that existed during early periods became significant negative in later periods. The 
variations in trends of correlation coefficients between GS-NDVI and GS-T calculated based on 10-year and 18-year moving windows (Figure S2-S3) were similar to those based on 14-year windows, suggesting the widths of the moving window has no obvious effects on trends of correlations.

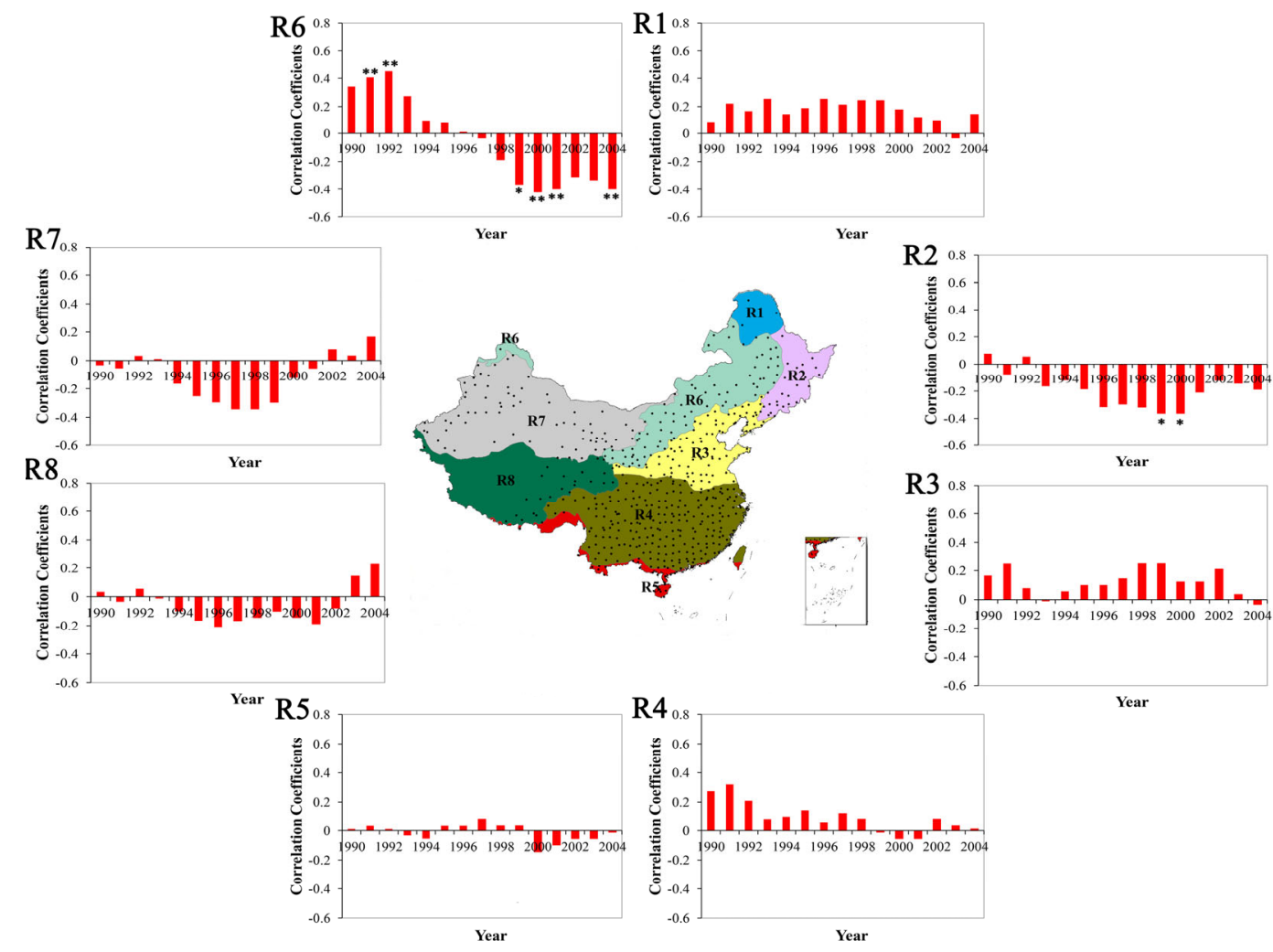

Figure 6 Variations of the relationship between NDVI and temperature with 14-year moving windows in eight sub-regions over the past 28 years. Correlations between NDVI and temperature are spatially heterogeneous. Correlations with $p<0.1,<0.05$ and $<0.01$ are marked with asterisks.

\subsection{Granger causality cause of temperature to vegetation growth}

To investigate the potential mechanism of impacts of temperature to vegetation growth, Granger causality links between GS-T and GS-NDVI were examined during two periods, as shown in Figure 7. GS-T was the positive granger cause of GS-NDVI in 1984-1997 and negative in the later 14 years (Figure 7a1). Despite the negative effect of GS-T on GS-NDVI during 1998-2011 had not been observed by Kendall-tau correlation analysis, it could be detected by Pearson's correlation analysis, as shown in Figure S4. The significant positive relationship between GS-T and GS-NDVI during 1984-1997 has been converted to weak negative relationship during 1998-2011. The Granger causality test further evidences the changing response of growing season vegetation growth to temperature shifts.

Regionally, during the period 1984-1997, GS-T was the granger cause of GS-NDVI in R5 and R7, with positive and negative correlations, respectively (Figure 7b1). During the period 1998-2011, significant causal link was only found for R5 with negative relationship (Figure 
7c1). The above results indicate that, the positive effects of growing season temperature on vegetation growth for rainforests during the first period has been converted to negative impacts in later period, and the negative impacts from temperature observed in temperate deserts in the first period has disappeared in the later period.
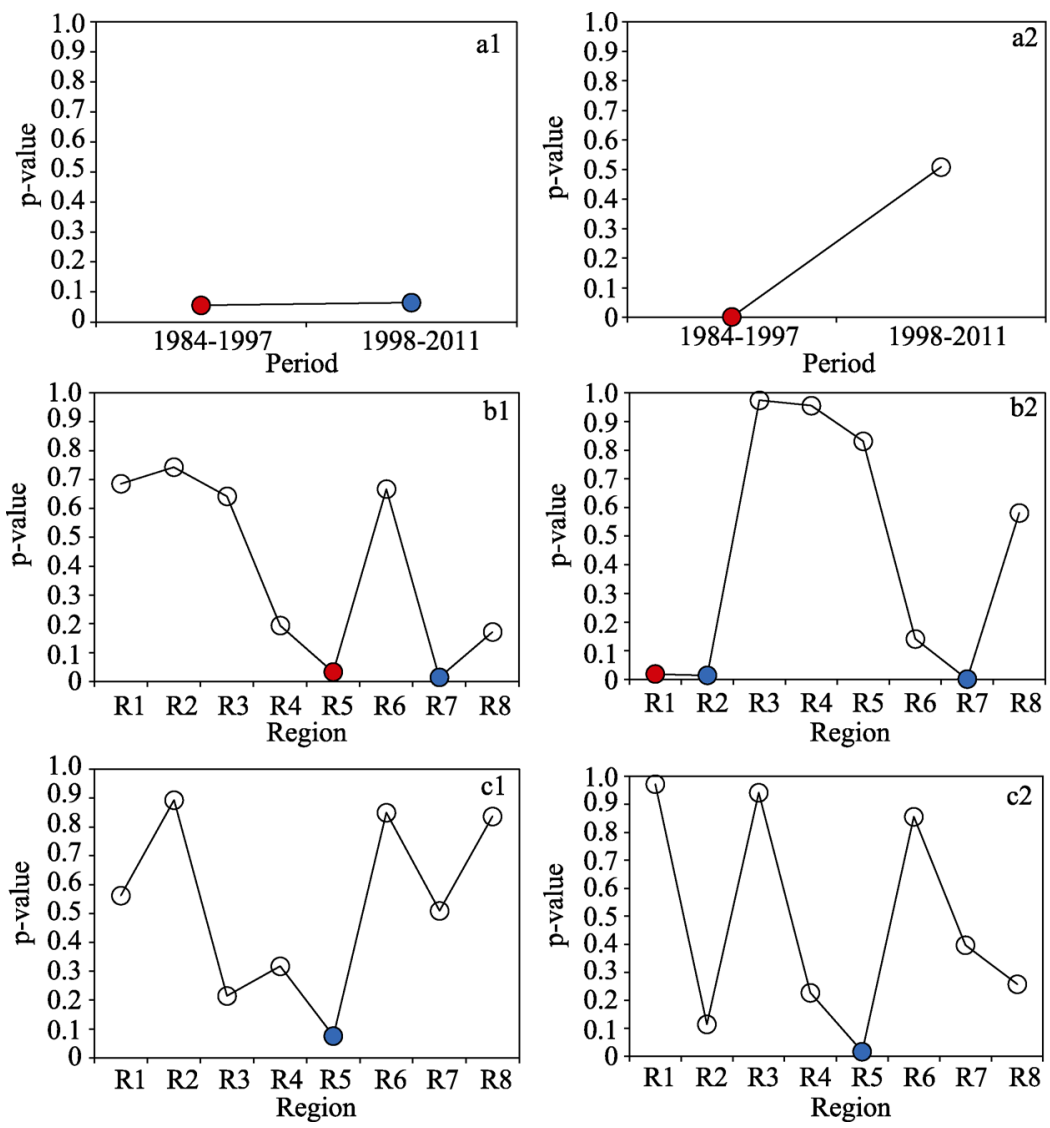

Figure 7 Granger causality tests between growing season NDVI and responding temperature during periods of 1984-1997 and 1998-2011 on national (a) and regional scale (b-c). (a1) GS-T granger cause GS-NDVI and (a2) vice versa; (b1) GS-T granger cause GS-NDVI in 1984-1997 and (b2) vice versa; (c1) GS-T granger cause GS-NDVI in 1998-2011 and (c2) vice versa. Color-circles indicate the p-value below 0.1 which means a significant causal link between variables, and red color means a positive correlation between GS-NDVI and GS-T, while the blue one indicates a negative correlation.

\section{Discussion}

Though the annual and seasonal warming shifts have been investigated by several studies, few of them have focused on its effects during the growing season. According to Wang et al.'s (2010) study, the temperature shift in China was not obvious, and temperature continued to increase from 1998 to 2008. In contrast, Li et al.'s (2015) study reported the opposite result, suggesting that the decrease in the annual mean maximum temperature caused a decrease in the overall mean temperature. This study provides evidence of a reduction in the rate of warming during the growing season in some regions of China over recent decades. A warming to cooling shift was obvious during the growing season in northern and northeast- 
ern regions of China, but in southern regions and the Qinghai-Tibet Plateau, an opposite shift was identified. The positive relationship between GS-NDVI and GS-T during 1984-2007 had been greatly weakened during 1998-2011 on national scale. This declined relationship was further verified by Granger causality test, suggesting the high sensitivity of vegetation growth to temperature change.

The results of this study confirm Piao et al.'s (2014) finding that the positive effects of GS-T on vegetation growth above $30^{\circ} \mathrm{N}$ are weakening. They attributed this phenomenon to increasing drought conditions (Piao et al., 2014). Here, to explore whether the change of response of GS-NDVI to GS-T was caused by the sensitivity of vegetation growth to other climate variables, such as precipitation, solar radiation, $\mathrm{CO}_{2}$ concentration etc. Causal links between GS-NDVI and GS-P, GS-R and GS- $\mathrm{CO}_{2}$ were also detected by Granger causality test to identify the main climate driver of vegetation growth, as shown in Figure 8, Figure S5-S6 and Table 1. The causal relationships between GS climate variables and GS-NDVI vary by periods and by vegetation regions. China as a whole, both GS-T and GS-R were the positive granger causes of GS-NDVI in the period 1984-1997, while the granger causes of
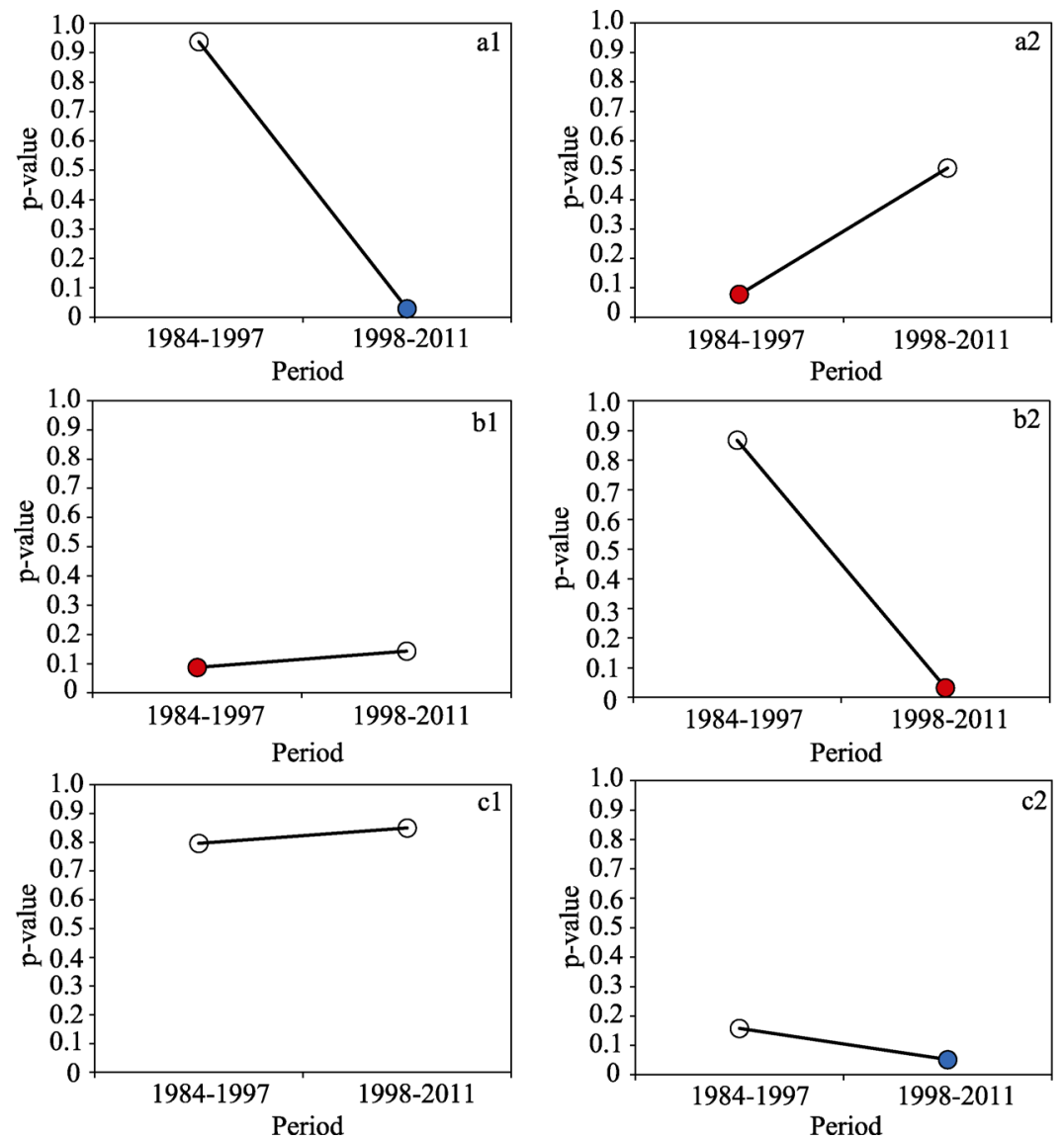

Figure 8 Granger causality tests between growing season NDVI and responding precipitation (a), radiation (b) and $\mathrm{CO}_{2}$ concentration (c) during the periods 1984-1997 and 1998-2011 on national scale. (a1) GS-P granger cause GS-NDVI and (a2) vice versa; (b1) GS-R granger cause GS-NDVI and (b2) vice versa; and (c1) GS-CO granger cause GS-NDVI and (c2) vice versa. Color-circles indicated the p-value below 0.1, and red color means a positive correlation between GS-NDVI and GS-climate variables, while the blue one indicates a negative correlation. 
Table 1 Results of Granger causality tests from GS-climate variables to GS-NDVI for whole China and eight vegetation type regions

\begin{tabular}{lcc}
\hline \multicolumn{1}{c}{ Regions } & \multicolumn{2}{c}{ Periods } \\
\cline { 2 - 3 } China as a whole & $1984-1997$ & $\mathrm{~T}(-), \mathrm{P}(-)$ \\
R1 (Coniferous forest region) & $\mathrm{T}(+), \mathrm{R}(+)$ & $\mathrm{P}(-)$ \\
R2 (Broadleaf-coniferous mixed forest region) & $\mathrm{P}(-), \mathrm{C}(+)$ & $\mathrm{R}(+)$ \\
R3 (Deciduous broadleaf forest region) & & $\mathrm{T}(-)$ \\
R4 (Evergreen broadleaf forest region) & \\
R5 (Rainforest region) & $\mathrm{T}(+), \mathrm{C}(-)$ & $\mathrm{P}(+), \mathrm{C}(+)$ \\
R6 (Temperate grasslands region) & $\mathrm{T}(-)$ & $\mathrm{C}(-)$ \\
R7 (Temperate desert region) & & \\
R8 (Qinghai-Tibet Plateau alpine meadow region) & & \\
\hline
\end{tabular}

GS-NDVI in the latter 14 years (1998-2011) were GS-T and GS-P, with negative correlation. Despite the precipitation experienced little change over China during the past 3 decades, drought extremes increased dramatically. Peng et al.'s (2011) study suggested that enhanced drought stress in north China limited the vegetation growth since the 1990s. Furthermore, comparing to the early period, the weakened impacts from climate variables were found for the later period, indicating increasing influences from other factors, such as human associated activities. Hence, we speculate that the reduced impacts from solar radiation and enhanced influences from precipitation and human activities should be responsible for the shift in response of vegetation growth to recent temperature change on national scale.

Controlling climate factors of vegetation growth were also identified in each vegetation type region. As reported by previous studies (Fang et al., 2004; Peng et al., 2011; Zhou et al., 2014), driving forces of vegetation growth differ greatly over China. For example, GS-T was the granger causes of GS-NDVI in R5 and R7, whereas GS-P and GS- $\mathrm{CO}_{2}$ were granger causes of GS-NDVI in R1 and R6 during 1984-1997. In light of previous knowledge, R5 is temperature constrained vegetation growth region (Fang et al., 2004; Peng et al., 2011), the shift of GS-T effect on GS-NDVI from positive to negative can be explained as follows: a certain degree of temperature rise is advantageous to the growth and development; however, with the continuous warming over the past centuries, the high temperature may reach and exceed a threshold for current vegetation and will be harmful for vegetation growth (Shaver et al., 2000). For example, a study on the response of grassland to climate change in North Arizona indicated a nonlinear response of vegetation growth to warming during initial stages; but after a certain time period, the positive effects of warming on vegetation growth declined progressively due to warming related plant community alteration, soil nitrogen turnover, etc. (Wu et al., 2012). In addition, vegetation growth should also be depressed by warming related increasing drought stress (Peng et al., 2011; Xu et al., 2012). R7 is a typical water limited vegetation growth area. The disappeared negative influence of temperature on vegetation growth in this region should be attributed to the releasing warming condition, which should alleviate warming-induced drought stress.

The above analysis also indicates the increase impacts from human associated activities. Even in the early period, vegetation activities in R2, R3 and R4 seem not to be driven by 
studied climate variable. This can be supported by a recent investigation that claimed socioeconomic factors, such as population and GDP, were main driving forces of vegetation growth in China during 2000-2010 (Lü et al., 2015). Other human activities such as ecological restoration projects, land-use changes, and agricultural activities may also influence the relationship between vegetation growth and climate variables. Over the past several decades, Chinese government carried out a series of ecological engineering programs (e.g. Three-North Shelter Forest Program, Grain for Green Program, Beijing-Tianjin Sand Source Control Program), and a majority of them was launched since 2000. Their positive effects on vegetation growth have been confirmed by monitoring studies (Piao et al., 2005; Xiao, 2014). Urban expansion should also be a reason for regional vegetation change. During the past 20 years, urban areas increased by approximately 2 -fold, and most rapid expansion was observed in coastal provinces (Wang et al., 2012). The Yangtze River Delta is one of the areas experienced most rapid urbanization, but the incomplete urbanization increased vegetation degradation in this region (Hou et al., 2014). Monitoring study showed that urbanization had caused deterioration of urban vegetation across most large cities in China (Sun et al., 2011). It needs to be noted that impacts from urbanization on vegetation growth were usually confined in local scales, but could not be a major driver of national level vegetation change.

In addition, strong impacts of vegetation conditions on climate were also observed based on Granger causality test, suggesting interactions between climate factors and vegetation growth (Figures 7 and 8, and Figure S5-S6). Taking GS-T as an example, during 1984-1997, GS-NDVI was a significant positive granger cause of GS-T, illustrating enhanced vegetation activities should also be responsible for the surface temperature increase during this period. They can be explained by the stronger warming effect caused by decreased surface albedo associated with enhanced vegetation than the cooling effect of increased evapotranspiration (Loarie et al., 2011). However, a stronger cooling effect of surface greening had been also observed in the Qinghai-Tibet Plateau and north China (Shen et al., 2015; Jiang et al., 2015). This inverse NDVI-T relationship should partly contribute to the observed weakening relationship between two variables, especially for growing season (Ge et al., 2015; Shen et al., 2015).

\section{Conclusions}

Over the past three decades, China has experienced significant warming, which was considered as a great contribution to China's greening. However, this warming trend is nonlinear with great shifts, and how vegetation growth response to temperature trend shift is unclear. This study comprehensively examined the response of vegetation growth to shift in temperature trend and explored the potential mechanism under the changed correlation between temperature and vegetation growth. The main results are listed as follows:

1) Obvious shifts in growing season temperature trends were observed over China between periods of 1984-1997 and 1998-2011. Warming to cooling shifts were found in north and northeast China, with cooling to warming shifts in south and west China.

2) China as a whole, the positive correlation between growing season temperature and vegetation had been significantly weakened over the past three decades, suggesting declined sensitivities of vegetation growth to temperature. 
3) Through the comprehensive analysis of growing season vegetation growth and corresponding climatic variables between periods of 1984-1997 and 1998-2011, the reduced impacts from solar radiation and enhanced influences from precipitation and human activities should be responsible for the shift in response of vegetation growth to recent temperature change on national scale.

Uncertainties remain in results from this study, which may be caused by following reasons: firstly, despite the reliability of AVHRR NDVI3g dataset used here has been validated by comparing with other remote sensing based dataset (eg. MODIS) by many studies (Zeng et al., 2013), satellite-based data always includes uncertainty due to data processing algorithm, sun-sensor-surface viewing geometries, atmospheric conditions, and sensor performance (Jiang et al., 2013). Further validations relying on field observed vegetation conditions (e.g., NPP) are still needed. Secondly, uncertainties may also be produced by methods used, for example, errors associated with divergence data sources, grid data interpolation, the choice of study windows etc. Thirdly, in this study, we only considered responses of NDVI to growing season climate change, and ignored influences from pre-growing season climate conditions ( $\mathrm{Wu}$ et al., 2015). Fourthly, the complex mechanisms behind the vegetation-climate interconnections have not been fully understood which leads to the difficulty in distinguishing and quantifying this bi-direction effect. Considering the above-mentioned issues, more in-depth investigations are still needed.

\section{Additional information}

Supplementary information accompanies this paper online.

\section{References}

Bhatt U S, Walker D A, Raynolds M K et al., 2010. Circumpolar Arctic tundra vegetation change is linked to sea ice decline. Earth Interactions, 14(8): 1-20.

Bhatt U S, Walker D A, Raynolds M K et al., 2013. Recent declines in warming and vegetation greening trends over Pan-Arctic Tundra. Remote Sensing, 5(9): 4229-4254.

Boykoff M T, 2014. Media discourse on the climate slowdown. Nature Climate Change, 4(3): 156-158.

Brown M T, Pinzón J E, Didan K et al., 2006. Evaluation of the consistency of long-term NDVI time series derived from AVHRR, SPOT-vegetation, SeaWiFS, MODIS, and Landsat ETM+ sensors. IEEE Transactions on Geoscience and Remote Sensing, 44(7): 1787-1793.

Chen X Y, Tung K K, 2014. Varying planetary heat sink led to global-warming slowdown and acceleration. Science, 345(6199): 897-903.

Ding M J, Li L H, Zhang Y L et al., 2015. Start of vegetation growing season on the Tibetan Plateau inferred from multiple methods based on GIMMS and SPOT NDVI data. Journal of Geographical Sciences, 25(2): 131-148.

Ding M J, Zhang Y L, Liu L S et al., 2007. The relationship between NDVI and precipitation on the Tibetan Plateau. Journal of Geographical Sciences, 17(3): 259-268.

Dong L, Zhang M, Wang S, et al., 2015. The freezing level height in the Qilian Mountains, northeast Tibetan Plateau based on reanalysis data and observations, 1979-2012. Quaternary International, 380: 60-67.

Fang J Y, Piao S L, He J S et al., 2004. Increasing terrestrial vegetation activity in China, 1982-1999. Science in China Series C: Life Sciences, 47(3): 229-240.

Ge Q S, Wang H J, Dai J H, 2015. Phenological response to climate change in China: A meta-analysis. Global Change Biology, 21(1): 265-274.

Granger C W J, 1969. Investigating causal relations by econometric models and crossspectral methods. 
Econometrica, 37(3): 424-438.

Holben B N, 1986. Characteristics of maximum-value composite images from temporal AVHRR data. International Journal of Remote Sensing, 7(11): 1417-1434.

Hou M T, Hu Y H, He Y T, 2014. Modifications in vegetation cover and surface albedo during rapid urbanization: A case study from South China. Environmental Earth Sciences, 72(5): 1659-1666.

Jiang B, Liang S L, Yuan W P, 2015. Observational evidence for impacts of vegetation change on local surface climate over northern China using the Granger causality test. Journal of Geophysical Research: Biogeosciences, 120(1): 1-12.

Jiang N, Zhu W Q, Zheng Z T et al., 2013. A comparative analysis between GIMSS NDVIg and NDVI3g for monitoring vegetation activity change in the Northern Hemisphere during 1982-2008. Remote Sensing, 5(8): 4031-4044.

Kaufmann R K, Zhou L, Myneni R et al., 2003. The effect of vegetation on surface temperature: A statistical analysis of NDVI and climate data. Geophysical Research Letters, 30(22): 2147.

Kendall M G, 1948. Rank Correlation Methods. London, UK: Charles Griffin, 108.

Kosaka K, Xie S P, 2013. Recent global-warming hiatus tied to equatorial Pacific surface cooling. Nature, 501(7467): 403-407.

Lü Y H, Zhang L W, Feng X M et al., 2015. Recent ecological transitions in China: Greening, browning, and influential factors. Scientific Reports, 5.

Li Q X, Yang S, Xu W H et al., 2015. China experiences the recent warming hiatus. Geophysical Research Letters, 42(3): 889-898.

Li S S, Yan J P, Liu X Y et al., 2013. Response of vegetation restoration to climate change and human activities in Shaanxi-Gansu-Ningxia Region. Journal of Geographical Sciences, 23(1): 98-112.

Liu X F, Zhang J S, Zhu X F et al., 2014. Spatiotemporal changes in vegetation coverage and its driving factors in the Three-River Headwaters Region during 2000-2011. Journal of Geographical Sciences, 24(2): 288-302.

Loarie S R, Lobell D B, Asner G P et al., 2011. Direct impacts on local climate of sugar-cane expansion in Brazil. Nature Climate Change, 1(2): 105-109.

Meehl G A, Teng H, Arblaster J M, 2014. Climate model simulations of the observed early-2000s hiatus of global warming. Nature Climate Change, 4(10): 898-902.

Mosedale J T, Stephenson B D, 2005. Granger causality of coupled climate processes ocean feedback on the North Atlantic Oscillation. Journal of Climate (Special Section), 19: 1182-1194.

Nemani R R, Keeling C D, Hashimoto H et al., 2003. Climate-driven increases in global terrestrial net primary production from 1982 to 1999. Science, 300(5625): 1560-1563.

Peng S S, Chen A P, Xu L et al., 2011. Recent change of vegetation growth trend in China. Environmental Research Letters, 6(4): 044027.

Piao S L, Cui M D, Chen A P et al., 2011. Altitude and temperature dependence of change in the spring vegetation green-up date from 1982 to 2006 in the Qinghai-Xizang Plateau. Agricultural and Forest Meteorology, 151(12): 1599-1608.

Piao S L, Fang J Y, Liu H Y et al., 2005. NDVI-indicated decline in desertification in China in the past two decades. Geophysical Research Letters, 32: L06402. doi: 10.1029/2004GL021764.

Piao S L, Nan H J, Huntingford C et al., 2014. Evidence for a weakening relationship between interannual temperature variability and northern vegetation activity. Nature Communications, 5: 5018. doi: $10.1038 /$ ncomms6018.

Qi L, and Wang Y, 2012. Changes in the observed trends in extreme temperatures over China around 1990. Journal of Climate, 25(15): 5208-5222.

Pinzon J E, Tucker C J, 2010. GIMMS 3g NDVI set and global NDVI trends. Second Yamal Land-Cover Land-Use Change Workshop Arctic Centre (Rovaniemi, March).

Sen P K, 1968. Estimates of the regression coefficient based on Kendall's tau. Journal of the American Statistical Association, 63(324): 1379-1389.

Shaver G R, Canadell J, Chapin F S et al., 2000. Global warming and terrestrial ecosystems. BioScience, 50(10): $871-882$. 
Shen M, Piao S, Jeong S J, et al., 2015. Evaporative cooling over the Tibetan Plateau induced by vegetation growth. Proceedings of the National Academy of Sciences, 112(30): 9299-9304.

Sillitto G, 1947. The distribution of Kendall's $\tau$ coefficient of rank correlation in rankings containing tie. Biometrika, 36-40.

Sun J Y, Wang X H, Chen A P et al., 2011. NDVI indicated characteristics of vegetation cover change in China's metropolises over the last three decades. Environmental Monitoring and Assessment, 179(1-4): 1-14.

Thompson D M, Cole J E, Shen G T et al., 2014. Early twentieth-century warming linked to tropical Pacific wind strength. Nature Geoscience, 8(2): 117-121.

Tucker C, Pinzon J, Brown M et al., 2005. An extended AVHRR 8-km NDVI dataset compatible with MODIS and SPOT vegetation NDVI data. International Journal of Remote Sensing, 26(20): 4485-4498.

Ukkola A M, Prentice I C, Keenan T F et al., 2015. Reduced streamflow in water-stressed climates consistent with $\mathrm{CO}_{2}$ effects on vegetation. Nature Climate Change, 6: 75-78. doi: 10.1038/nclimate2831.

Wang L, Li C C, Ying Q et al., 2012. China's urban expansion from 1990 to 2010 determined with satellite remote sensing. Chinese Science Bulletin, 57(22): 2802-2812.

Wang S W, Wen X Y, Luo Y et al., 2010. Does the global warming pause in the last decade: 1999-2008. Advances in Climate Change Research, 6: 95-99.

Wang W, Anderson B T, Kaufmann R K et al., 2004. The relation between the North Atlantic Oscillation and SSTs in the North Atlantic Basin. Journal of Climate, 17: 4752-4759.

Wang X H, Piao S L, Ciais P et al., 2014. A two-fold increase of carbon cycle sensitivity to tropical temperature variations. Nature, 506(7487): 212-215.

Wu D H, Zhao X, Liang S L et al., 2015. Time-lag effects of global vegetation responses to climate change. Global Change Biology, 21(9): 3520-3531.

Wu R, Kinter III J, Kirtman B P, 2005. Discrepancy of interdecadal changes in the Asian region among the NCEP-NCAR reanalysis, objective analyses, and observations. Journal of Climate, 18(15): 3048-3067.

Wu R, Yang S, Liu S, et al., 2010. Changes in the relationship between Northeast China summer temperature and ENSO. Journal of Geophysical Research: Atmospheres, 115(D21).

Wu Z, Dijkstra P, Koch G W et al., 2012. Biogeochemical and ecological feedbacks in grassland responses to warming. Nature Climate Change, 2(6): 458-461.

Xiao J F, 2014. Satellite evidence for significant biophysical consequences of the "Grain for Green" Program on the Loess Plateau in China. Journal of Geophysical Research: Biogeosciences, 119(12): 2261-2275.

Xu X T, Piao S L, Wang X H et al., 2012. Spatio-temporal patterns of the area experiencing negative vegetation growth anomalies in China over the last three decades. Environmental Research Letters, 7(3): 035701.

Yin G, Hu Z Y, Chen X et al., 2016. Vegetation dynamics and its response to climate change in Central Asia. Journal of Arid Land, 8(3): 375-388.

Zeng F W, Collatz G J, Pinzon J E et al., 2013. Evaluating and quantifying the climate-driven interannual variability in Global Inventory Modeling and Mapping Studies (GIMMS) Normalized Difference Vegetation Index (NDVI3g) at global scales. Remote Sensing, 5(8): 3918-3950.

Zhang L, Xiao J F, Li J et al., 2012. The 2010 spring drought reduced primary productivity in southwestern China. Environmental Research Letters, 7(4): 045706.

Zhang X Y, Hu Y F, Zhuang D F et al., 2009. NDVI spatial pattern and its differentiation on the Mongolian Plateau. Journal of Geographical Sciences, 19(4): 403-415.

Zhang X Z, Dai J H, Ge Q S, 2013. Variation in vegetation greenness in spring across eastern China during 1982-2006. Journal of Geographical Sciences, 23(1): 45-56.

Zhao X, Tan K, Zhao S et al., 2011. Changing climate affects vegetation growth in the arid region of the northwestern China. Journal of Arid Environments, 75(10): 946-952.

Zhou L M, Tucker C J, Kaufmann R K et al., 2001. Variations in northern vegetation activity inferred from satellite data of vegetation index during 1981 to 1999. Journal of Geophysical Research: Atmospheres, 106(D17): 20069-20083.

Zhou W, Gang C C, Chen Y Z et al., 2014. Grassland coverage inter-annual variation and its coupling relation with hydrothermal factors in China during 1982-2010. Journal of Geographical Sciences, 24(4): 593-611. 


\section{Supporting Information (SI)}
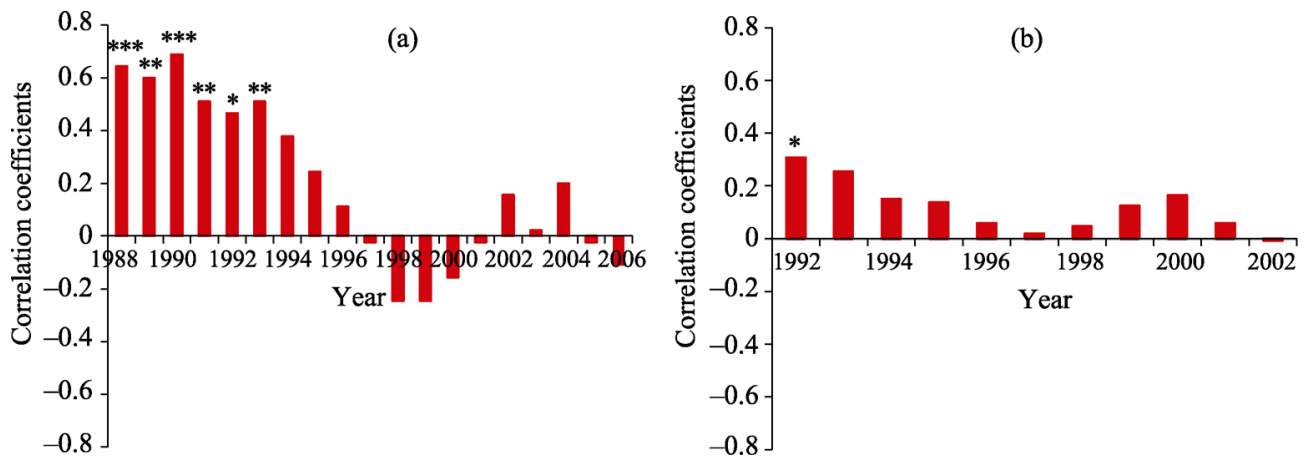

Figure S1 Variation of correlation coefficient between growing season NDVI and responding temperature during 1984 to 2011 with 10-year moving windows (a) 18-year moving windows (b). Correlations with $\mathrm{p}$-values $<0.1$, $<0.05$ and $<0.01$ are marked with asterisks.

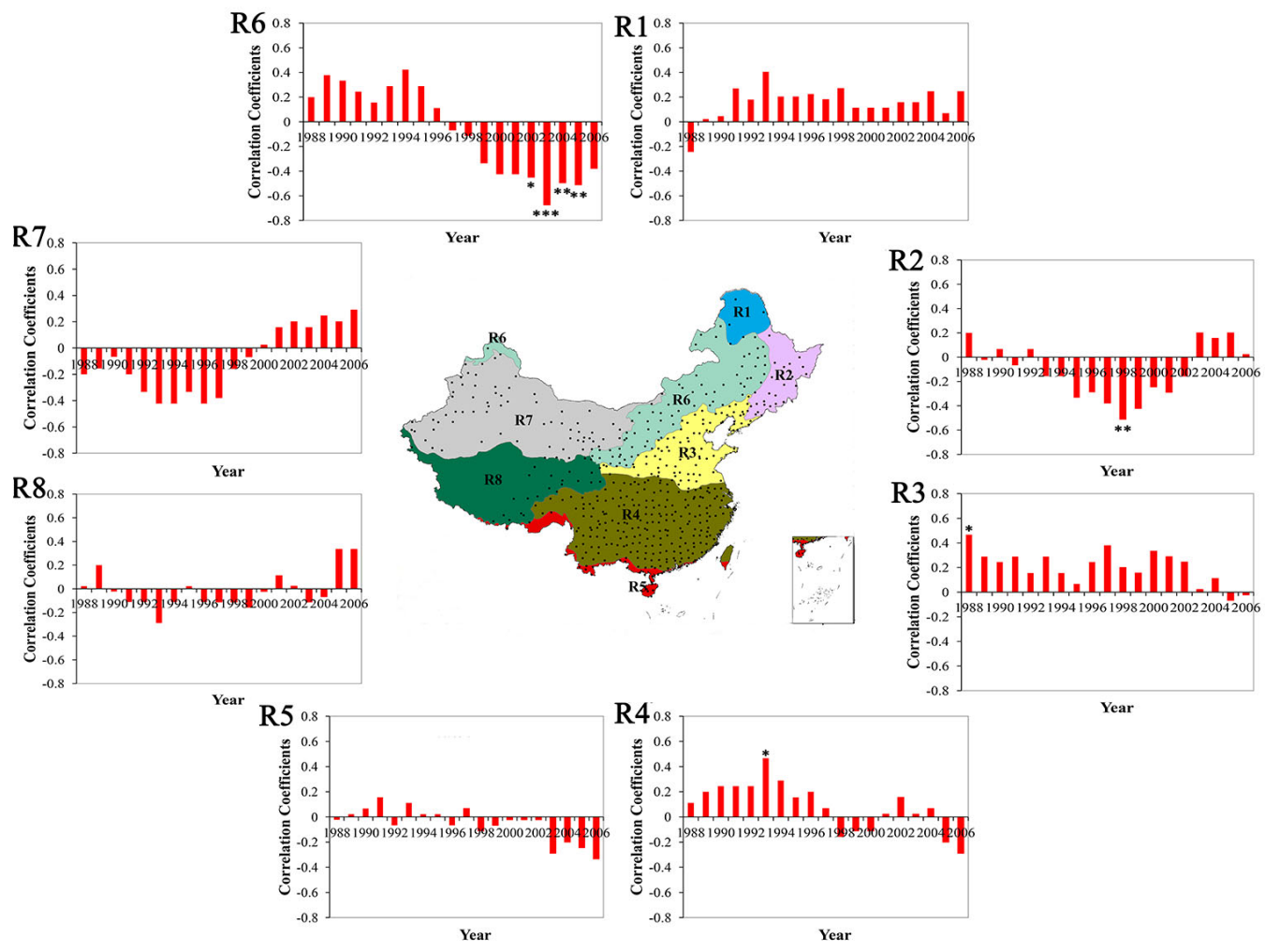

Figure S2 Variation of the relationship between NDVI and temperature with 10-year moving windows in eight sub-regions over the past 28 years. The correlations between NDVI and temperature are spatially heterogeneous. Correlations with p-values $<0.1,<0.05$ and $<0.01$ are marked with asterisks. 


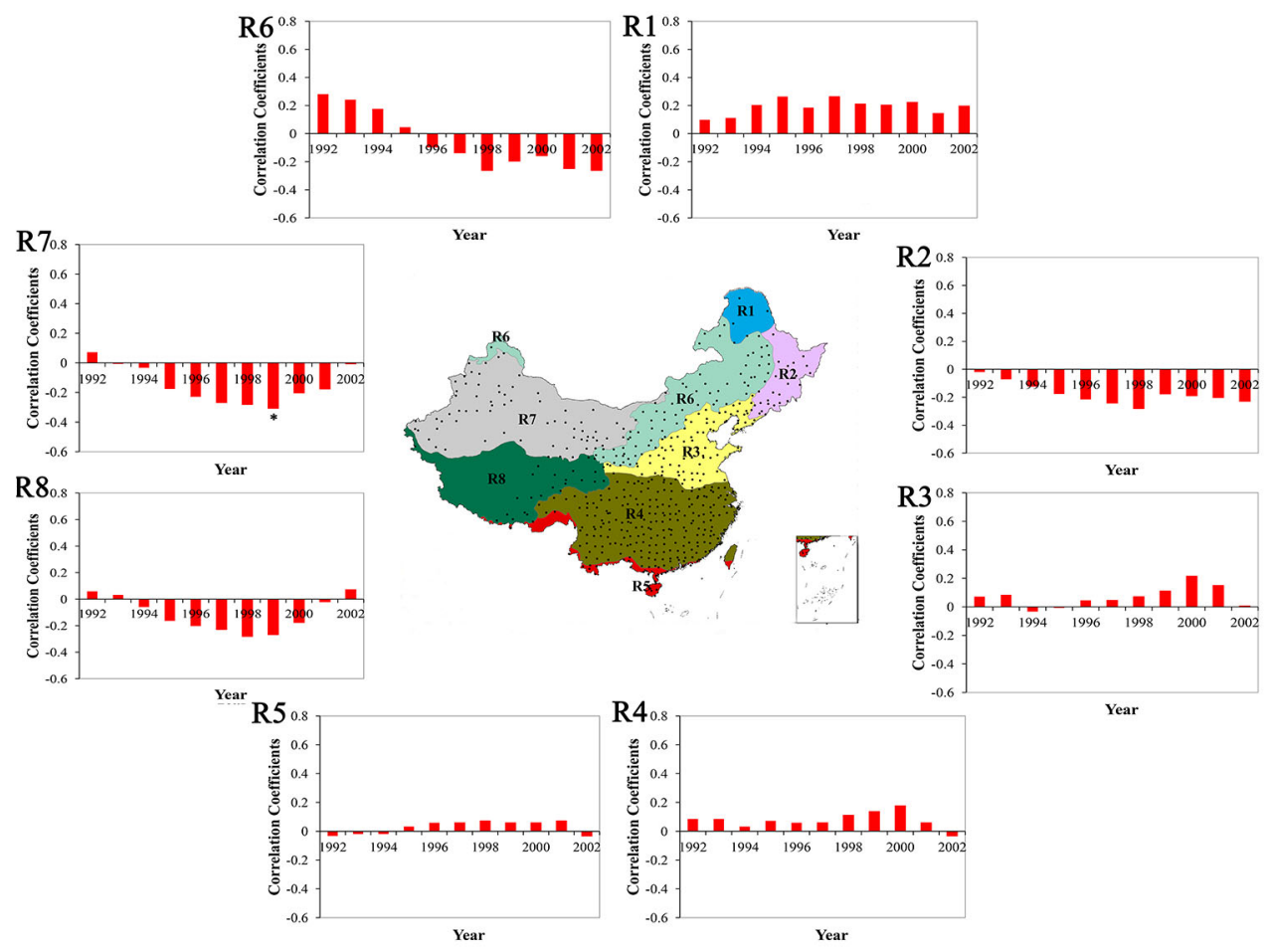

Figure S3 Variation of the relationship between NDVI and temperature with 18-year moving windows in eight sub-regions over the past 28 years. The correlations between NDVI and temperature are spatially heterogeneous. Correlations with p-values $<0.1,<0.05$ and $<0.01$ are marked with asterisks.

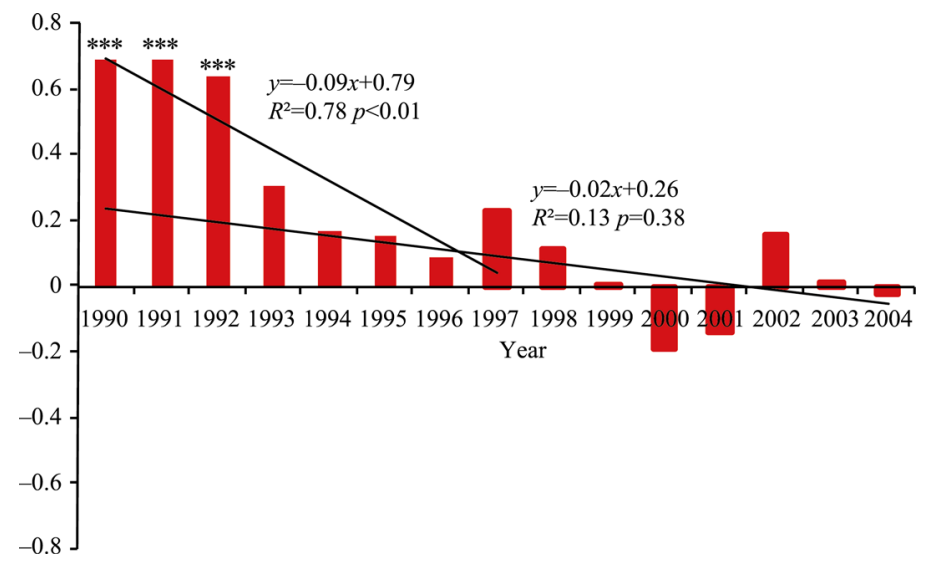

Figure S4 Variation of the relationship between NDVI and precipitation with 14-year moving windows in eight sub-regions over the past 28 years. The correlations between NDVI and precipitation are spatially heterogeneous. Correlations with $\mathrm{p}$-values $<0.1,<0.05$ and $<0.01$ are marked with asterisks. 

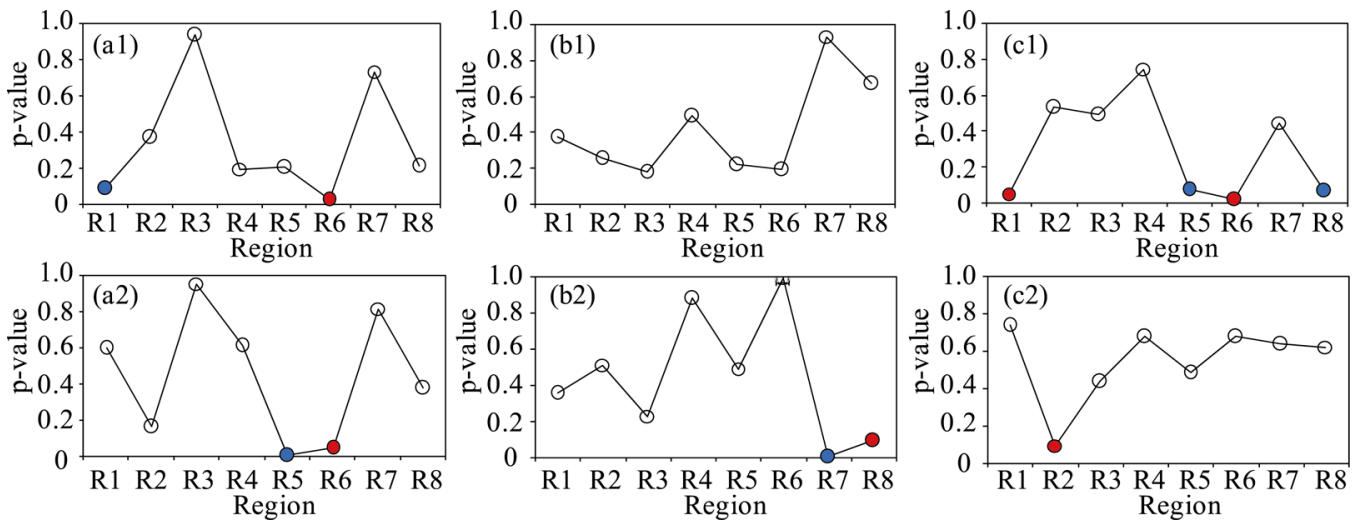

Figure S5 Granger causality tests between growing season NDVI and responding precipitation (a), radiation (b) and $\mathrm{CO}_{2}$ concentration (c) in 1984-1997 on regional scale. (a1) GS-P granger cause GS-NDVI and (a2) vice versa; (b1) GS-R granger cause GS-NDVI and (b2) vice versa; and (c1) GS- $\mathrm{CO}_{2}$ granger cause GS-NDVI and (c2) vice versa. Color-circles indicated the p-value below 0.1 , and red color means a positive correlation between GS-NDVI and GS- climate variables, while the blue one indicates a negative correlation.
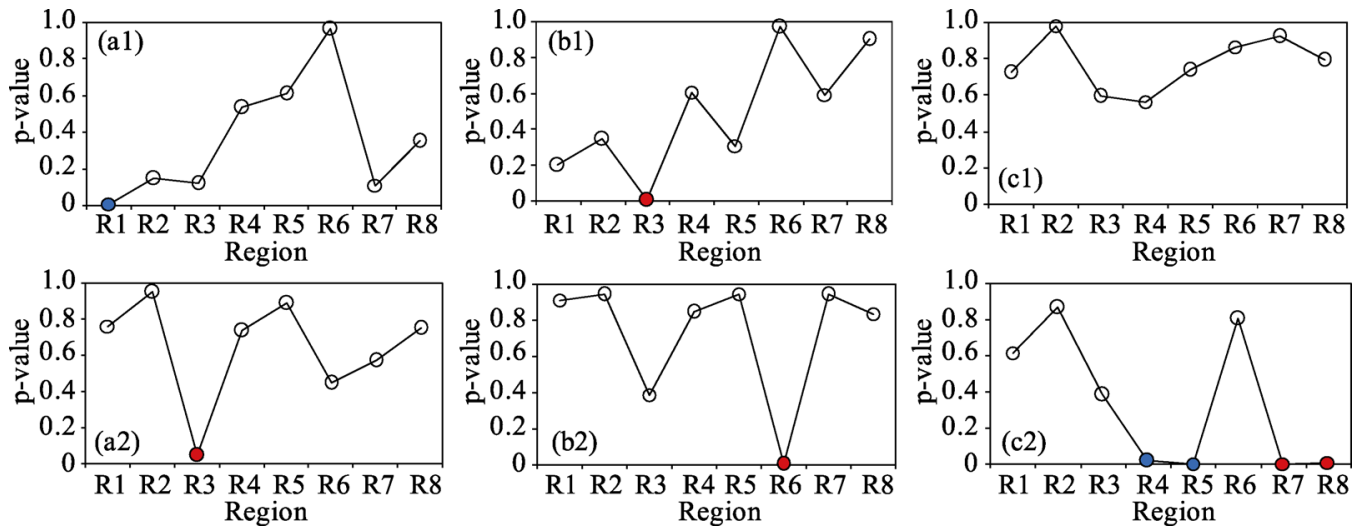

Figure S6 Granger causality tests between growing season NDVI and responding precipitation (a), radiation (b) and $\mathrm{CO}_{2}$ concentration (c) in 1998-2011 on regional scale. (a1) GS-P granger cause GS-NDVI and (a2) vice versa; (b1) GS-R granger cause GS-NDVI and (b2) vice versa; and (c1) GS-CO $\mathrm{CO}_{2}$ granger cause GS-NDVI and (c2) vice versa. Color-circles indicated the p-value below 0.1 , and red color means a positive correlation between GS-NDVI and GS- climate variables, while the blue one indicates a negative correlation. 